\title{
Artelogie
}

Recherche sur les arts, le patrimoine et la littérature de l'Amérique latine

\section{El campo de la fotografía y las imágenes del Brasil en los años 1970-80: entre el fotoperiodismo y la fotografía documental}

\section{Charles Monteiro}

\section{(2) OpenEdition}

\section{Journals}

Edición electrónica

URL: https://journals.openedition.org/artelogie/1086

DOI: 10.4000/artelogie.1086

ISSN: 2115-6395

Editor

Association ESCAL

Referencia electrónica

Charles Monteiro, «El campo de la fotografía y las imágenes del Brasil en los años 1970-80: entre el fotoperiodismo y la fotografía documental», Artelogie [En línea], 7 | 2015, Publicado el 15 abril 2015, consultado el 11 abril 2022. URL: http://journals.openedition.org/artelogie/1086 ; DOI: https://doi.org/ 10.4000/artelogie.1086

Este documento fue generado automáticamente el 11 abril 2022.

Association ESCAL 


\title{
El campo de la fotografía y las imágenes del Brasil en los años 1970-80: entre el fotoperiodismo y la fotografía documental
}

\author{
Charles Monteiro
}

\section{NOTA DEL AUTOR}

El presente texto es el fruto de la reflexión iniciada en un proyecto de investigación desarrollado con beca de investigación Senior de la CAPES 396813-8 (2013-14) en el Université de París 1, bajo la supervisión del Prof. Dr. Michel Poivert, y que continúa hoy con una beca PQ del CNPQ (2014-2016).

\section{El campo de la fotografía}

1 La investigación busca problematizar la reorganización del campo fotográfico en Brasil, en los años 1970, en especial, la producción de imágenes situadas entre los campos del fotoperiodismo y de la fotografía documental, en el contexto sociopolítico de un país en transformación, debido a la lucha por la abertura política y los movimientos sociales.

El campo de la fotografía en Brasil en los años 1970 se caracterizó por un proceso de expansión, profesionalización, al mismo tiempo que se hizo más complejo, tanto en el campo periodístico como en el campo artístico. Según Tadeu Chiarelli (2002, p. 132), a partir de los años 1950 la fotografía asumió definitivamente el lugar de las artes plásticas en la misión de constituir una imagen del Brasil y de los brasileros.

3 Los fotógrafos se comprometieron en la construcción de una nueva visión para la nación, muy diferente de aquella exhibición de las bellezas naturales, de los prodigios 
de la modernización del "desarrollismo" (o desenvolvimentismo) que marcaron los años $1950^{1}$.

4 Hacia el final de los años '60, surgía en las redacciones de los grandes vehículos editoriales una nueva "generación" de fotógrafos, que se comprometió tanto en las luchas políticas por la apertura democrática como por la valorización y organización de la profesión de fotógrafo en la prensa: por los créditos en la autoría de las fotos, elaboración de una tabla de honorarios, garantía de la posesión de los negativos y proposición de pautas por los fotoperiodistas (Benedicto, 1983, p.150-151). La reglamentación de la profesión de reportero fotográfico al servicio de la empresa periodística, fue estructurada por el Decreto-Ley 972/69, que trata de la profesión de periodista.

5 En este proceso, la prensa, y en especial, el fotoperiodismo tuvo un papel fundamental en la denuncia de la represión, de la censura y de las desigualdades sociales. La lucha por la tierra, las migraciones entre regiones/campo-ciudad, los problemas ecológicos, la explotación de los trabajadores, la pobreza en sus múltiples aspectos, las huelgas y la violencia policial, fueron algunos de los temas abordados en la producción fotográfica del período.

6 En Brasil, se observa una disputa en curso entre las "imágenes del poder" y las “imágenes de los movimientos sociales". Las imágenes del poder eran producidas por las Asesorías de Comunicación del Gobierno Federal y de los Gobiernos Estaduales, lo que el fotógrafo Luís Humberto (1983) llamaba, "liturgia del poder". El contenido de esas imágenes estaba asociado a la creación de significados y sentidos políticos ligados al nacionalismo, al mantenimiento del orden político, a la conquista, interiorización e integración del territorio nacional y a la doctrina de seguridad nacional. Estos significados políticos fueron expresados en fotografías de los generales y de los políticos ligados al partido ARENA en actos públicos, en las inauguraciones de grandes obras públicas (rutas, puentes, predios administrativos y obras viales urbanas), así como también en la propaganda laudatoria sobre la grandeza del país y de sus sucesos económicos en el contexto del llamado "milagro económico".

7 Por un lado, una nueva generación de fotógrafos va a privilegiar la producción de imágenes de los movimientos sociales, de la lucha en el campo, la precaria situación de los indígenas y de los desposeídos urbanos. Fotógrafos freelances intentaban esquivar la censura de la Policía Federal sobre los medios de comunicación y la autocensura de los vehículos de comunicación para resistir y oponerse a la dictadura militar. Algunos fueron forzados a suspender sus actividades y amenazados, otros fueron presos y torturados, pero consiguieron que sus fotografías fuesen publicadas en la prensa de gran difusión y, sobre todo, en la llamada prensa alternativa (sindical, cooperativas, etc.).

8 El mosaico de imágenes de la nación se complejizó, se dieron a conocer los grupos que habían permanecido en la invisibilidad o que figuraban de manera subordinada en la construcción de la imagen de la nación: los trabajadores, los agricultores pobres o los "sin tierra", los indígenas y otras minorías que exigían sus derechos. Aquellos que a partir de la segunda mitad del siglo XIX e inicio del XX fueron muchas veces considerados peligrosos o enfermos, que deberían ser controlados y educados por el Estado.

9 En el mismo período, la llamada prensa "alternativa" floreció ofreciendo una visión más crítica sobre las políticas del Régimen Militar, en la contramano de la censura de 
los órganos de información y de la autocensura de los editores de los grandes periódicos (Aguiar, 2008, p. 233-247).

Surgieron las cooperativas o colectivos de fotógrafos, que eran tanto espacios de trabajo alternativos a la gran prensa, como grupos de organización política y de lucha por la valorización de los fotógrafos: Focontexto (Porto Alegre, 1979), F4 (São Paulo, 1979) y Ágil Fotojornalismo (Brasilia, 1980) entre otras. La creación de agencias independientes de fotoperiodismo y de colectivos de fotografía permitió a los fotógrafos mayor libertad en la producción de notas, en la cobertura de los acontecimientos políticos más importantes del período, así como una mayor valorización de su trabajo (Carvalho, 2012, p. 15-18).

11 Según Coelho (2006, p. 93), la lucha de esos profesionales era por el reconocimiento de sus créditos autorales en las fotografías publicadas (lo que ocurría apenas en algunas revistas, como Realidad, Manchete y Veja), instituir una tabla de precios mínima para los fotógrafos freelances y el pago por la cesión de los derechos de publicación de las fotografías vendidas por las agencias.

En la década de 1970, se inicia un período de institucionalización del campo con la creación del Núcleo de Fotografía de la FUNARTE en 1979, con sede en Rio de Janeiro, transformado, en 1984, en el Instituto Nacional da Fotografía (INFOTO). La valorización de la fotografía en el plano internacional y nacional, así como la movilización de los profesionales llevó al gobierno a crear un órgano público responsable por organizar una política nacional para la fotografía (Coelho, 2006, p. 96). La preocupación de esos profesionales era hacia la preservación de acervos fotográficos que permitiesen reflexionar sobre la historia del Brasil y también el establecer la fotografía dentro del campo de las artes visuales. Para ello, proponían la organización de exposiciones, la publicación de libros, la realización de encuentros regionales y seminarios nacionales para discutir e implementar políticas públicas para la fotografía.

Otra gran cuestión fue la reivindicación de la autoría por los fotógrafos en los años 1970 y 1980. Un movimiento que puede observarse tanto en Francia como en América Latina. Frente a la creciente homogenización y masificación del foto-reportaje los fotógrafos buscaban afirmar un espacio de libertad y de creación, que se tradujo en una reivindicación autoral de sus imágenes.

El periódico y la revista no siempre fueron los mejores espacios de expresión de la creatividad, de la renovación del lenguaje fotográfico y de la afirmación de la figura de autor para los fotógrafos. Las exposiciones colectivas e individuales, las publicaciones de catálogos y, especialmente, de libros de fotografía por editoriales independientes, fueron las alternativas para la afirmación de esa figura de autor. Los deseos individuales de los fotógrafos se transformaron en colectivos y encontraron su vehículo de expresión en los sindicatos de fotógrafos y, sobre todo, en el Instituto de Fotografía de la FUNARTE.

15 Al lado de las políticas públicas para el área, creadas por la Funarte, también la iniciativa privada y el mercado del arte comenzó a valorizar y ampliar los espacios para la fotografía, como forma de expresión artística. Grandes empresas patrocinaron muestras nacionales, surgieron galerías especializadas en fotografía como la Fotoptica (SP, 1979-1996) y Luz e Sombra (RJ, 1979) entre otras (Peregrino; Magalhães, 2004, p. 94). 

São Paulo, se encargaron de difundir y discutir la producción de los fotógrafos ya consagrados y también de los jóvenes (Peregrino ; Magalhães, 2004, p. 94). El periódico Folha da Tarde del Grupo Periodístico Calda Júnior, de Porto Alegre, creó una sección sobre "Fotografía" con doble página todos los sábados, entre 1974 y 1976, editada por Assis Hoffmann, Luiz Carlos Felizardo y Eneida Serrano. publicaba el mayor número de periódicos y la Editora Abril asumía el liderazgo en el sector de revistas lanzando un conjunto de publicaciones (Realidade, Veja, Quatro Rodas y Placar), que emplearon un gran número de fotógrafos. En la revista Realidade trabajaban fotógrafos extranjeros como Cláudia Andujar, Maureen Bisilliat, George Love, Lew Parrela, entre otros, quienes abrirán camino para la renovación del lenguaje del fotoperiodismo brasilero con el uso del color (Peregrino ; Magalhães, 2004, p. 65).

El gran equipo de fotógrafos reunido para actuar en la revista Veja permitió la convivencia entre fotógrafos con experiencia y una nueva generación de fotoperiodistas. La revista también tenía sucursales regionales, donde trabajaban varios redactores, reporteros, fotógrafos contratados y free-lancers. Periódicos como el Estado de São Paulo, la Folha de São Paulo y el Jornal do Brasil, realizaron reformas editoriales y gráficas que privilegiaron el uso de la fotografía.

19 Para Fernandes Júnior (2003, p. 154), las revistas ilustradas producían un nuevo lenguaje fotográfico uniendo información y expresión, más allá de la fotografía de publicidad y del fotoperiodismo convencional lanzando profesionales como Walter Firmo, Luis Humberto, Assis Hoffmann y Evandro Teixeira entre muchos otros.

Estos fotógrafos se organizaron y propusieron nuevas pautas, dando una nueva visibilidad a la sociedad brasilera, al contrario de valorizar la teatralización del poder y los sucesos del milagro económico, pasaron a cubrir la violencia policial, la represión y la organización de los movimientos sociales, la depredación de la Amazonia, la marginalización de los grupos indígenas y de los afro-brasileros, la falta de viviendas, el crecimiento de las favelas y el empobrecimiento de las clases trabajadoras. Según Munteal, "las fotos de los poderosos en posiciones ambiguas y, muchas veces ridículas, las distorsiones en la imagen, una sensación de ampliación de la visión por la utilización de la lente grande angular, fueron [algunas] de las soluciones aplicadas por esa generación de fotógrafos" (2005, p. 138). Según Coelho (2006, p. 92), esta sería la primera generación de fotógrafos brasileros provenientes de las camadas medias urbanas, con formación universitaria.

\section{La enseñanza de la fotografía}

21 Inicialmente, la enseñanza-aprendizaje de la fotografía se daba en los fotoclubes, que remontan a las décadas de 1910 y 1920. El Photo Club Brasileiro (1923), con un lenguaje más tradicional fue un polo difusor del picturalismo, y el Foto Cine Clube Bandeirantes (1939), responsable por la introducción de la fotografía moderna en Brasil; fueron los dos principales espacios de formación de fotógrafos en Brasil en la primera mitad del siglo XX. Los miembros de los fotoclubes pertenecían a las camadas medias urbanas y, generalmente, tenían alguna otra profesión, dedicándose a la fotografía como actividad 
complementaria o hobby. Los fotoclubes editaban revistas, organizaban concursos, muestras y excursiones fotográficas.

En el caso de los fotoperiodistas el aprendizaje se daba en las propias redacciones de los periódicos y revistas. En los años 1930 y 1940, muchos extranjeros se radicaron en Brasil ayudando a crear la edición de fotografía en las revistas ilustradas. El fotógrafo consagrado observaba el interés del joven aprendiz y le daba algunas enseñanzas en los intervalos de sus actividades en la redacción.

En los años 1960, las revistas Realidade y Veja pasaron a dar cursos propios de formación para reporteros y periodistas buscando calificar el trabajo, así como crear un lenguaje nuevo para un periodismo más moderno y ágil en el contexto de un país en transformación y con una demanda cada vez mayor de información y entretenimiento.

En los años 1960, se crearon los primeros cursos regulares de fotografía en Brasil. En 1962, la Escuela de Periodismo de la Fundação Cásper Libero presenta la disciplina de fotografía en su currículo. En los años 1960, también surgiría el curso técnico de fotografía en el Servicio Nacional de Aprendizaje Comercial (SENAC) de São Paulo. (Ver Peregrino \& Magalhães).

En 1966, se creó la disciplina de "Fotografía" en la Escuela de Comunicación y Artes de la Universidad de São Paulo. En el mismo año, la Facultad de Comunicación de la Universidad de Brasilia crea la disciplina "Técnica y Práctica de la Fotografía" (Magalhães; Peregrino, 2004, p. 68).

En 1968, la Escuela de Comunicaciones de la Universidad Federal do Rio de Janeiro ofrecía entre sus seis habilitaciones: periodismo gráfico y periodismo visual

Con la reforma universitaria de 1968, la formación en los cursos de Periodismo dejó de tener su énfasis en las Ciencias Humanas y pasó a ser más técnica, orientada hacia el mercado de trabajo. Con esto, la fotografía, entendida como técnica y herramienta de trabajo del periodista pasó a ser más valorizada, transformándose en una disciplina administrada en todos los cursos de graduación en Comunicación Social de Brasil. También se crearon cursos de fotografía en las carreras de Arquitectura como forma de estudio de los lenguajes arquitectónicos.

Desde la creación del Núcleo de Fotografía (1979) y, posteriormente, Instituto Nacional de Fotografía (1985) de la FUNATE, la enseñanza de la fotografía era uno de los diez principales objetivos para una política nacional de fotografía. (FUNARTE, 1986, p. 9-11).

A partir de 1983, el Infoto realizó una serie de muestras colectivas regionales (1983-89) y las Semanas Nacionales de la Fotografía en varios estados (RJ, DF, PE, PA, PR, MG y SP) ${ }^{3}$. Las semanas promovían cursos, conferencias, exposiciones y publicaciones de catálogos, que permitían profundizar en el debate y el intercambio entre fotógrafos (Coelho, 2006, p. 96). Se otorgaron premios y se crearon dos programas de becas para estimular proyectos en el área de enseñanza, documentación, monografías y procesos alternativos.

La II Semana Nacional de Fotografía promovida por la FUNARTE en Brasilia, del 15 al 19 de agosto de 1983, contó con una mesa-redonda específica sobre Enseñanza de la Fotografía, teniendo como participantes: Cláudio Feijó, Luiz Venturelli, Patrícia Canetti, Ricardo de Hollanda, Rosary Esteves.

31 Mientras, los problemas relacionados a las limitaciones en la formación de los fotógrafos y en la enseñanza de la fotografía en Brasil se mantuvieron en las décadas 
siguientes. Según Luís Humberto ${ }^{4}$, en el libro Fotografía: Universos y Arrabaldes (1983) publicado por la Colección Luz \& Reflexión, la enseñanza de la fotografía se daba :

de modo general en la base del autodidactismo sufrido, del aprendizaje medieval en los laboratorios de los periódicos y en los foto clubes. Por todos esos caminos, de forma insuficiente y defectuosa. Insuficiente técnica y culturalmente, pues las informaciones obtenidas son siempre incompletas, cuando no retenidas. Defectuosa porque adquieren una visión deformada de la profesión, no llegan casi nunca a tener la consciencia de su importancia y responsabilidad. De cualquier forma, el aprendizaje es casi siempre desarrollado sin ninguna preocupación en cuanto al valor de la fotografía dentro de un contexto social, como forma de comunicación o en lo respecta a los medios industriales de producción. Se valoriza excesivamente el perfeccionamiento artesanal... (HUMBERTO, 1983, p. 23-24). En julio de 1985, en Belo Horizonte (MG), la FUNARTE propuso una mesa-redonda sobre "La universidad brasilera y la enseñanza de fotografía" en la 37ª Reunión de la Sociedad Brasilera para el Progreso de la Ciencia (SBPC). En la apertura de la mesa-redonda, el fotógrafo Pedro Vasquez, Director del Instituto Nacional de Fotografía (INFOTO), coincidía con este punto de vista:

La enseñanza de la fotografía en Brasil evolucionó en un cuadro extremamente desfavorable. A pesar de algunas iniciativas heroicas, [...], la falta de escuelas bien equipadas, de un currículo adecuado a la realidad nacional y el alto costo del material fotográfico, obligan a la mayor parte de los interesados a perder tiempo y energía en un autodidactismo penoso y dispersivo. (VASQUEZ, 1985, p. 4)

La intención del Director de la FUNARTE Pedro Vasquez era llevar la polémica hacia dentro de la Universidad. Debatir las experiencias existentes y proponer la elaboración de un currículo mínimo para la enseñanza de la fotografía. Además, se debe recordar que la profesión de fotógrafos no estaba legalizada (su ejercicio no estaba reglamentado y no poseía un estatuto propio) y la ley de derechos autorales no se cumplía en los periódicos, revistas y editoras en la reproducción, alteración y reventa de fotografías.

No obstante, surgieron varias propuestas para la reorganización de la enseñanza de la fotografía. Luis Humberto afirmaba (1983, p. 27) que la fotografía no debería restringirse a ser enseñada en las escuelas técnicas y en la universidad, sino que debería ser materia enseñada desde la escuela fundamental para la formación del ciudadano en una sociedad donde la tecnología y los medios de comunicación se transformaron en algo tan influyente. Para él, la fotografía tiene un potencial libertador, ya que proporciona un nuevo lenguaje de expresión y nuevos hábitos visuales, que no pueden estar restringidos al "feudo cultural de tan pocos" en la universidad (1983, p. 27).

38 Según Carmem Regina de Vargas (Funarte, 1985, p. 9), de la Coordinación de Enseñanza e Investigación de la Funarte en los años 1980, en los currículos de Comunicación Social la enseñanza estaba reducida al dominio de algunas técnicas de fotografiar en detrimento de la reflexión sobre el lenguaje fotográfico y su campo semántico. La enseñanza de fotografía debería ir más allá de las aulas sobre el uso de la máquina fotográfica, de las técnicas de laboratorio e incluir la reflexión sobre el sujeto fotógrafo en el currículo.

Para Juan Carlos Sândi Aramayo (Funarte, 1985, p. 15), fotógrafo y profesor del Curso de Comunicación Social de la Universidad Federal de Minas Gerais (UFMG), el debate 
debería comenzar con un cuestionamiento amplio sobre para qué, por qué y cómo enseñar fotografía en la universidad. La fotografía tiene múltiples funciones en la sociedad, siendo una de ellas la artística, relacionada a la enseñanza de la técnica, de la historia y de la estética de la fotografía. Por lo tanto, la enseñanza de fotografía no debería restringirse a la dimensión artística y ser concebida como una instancia privilegiada para facilitar la reflexión. La fotografía posibilitaría la comprensión de la práctica social de los signos visuales contemporáneos presentes en el cine, en la televisión, en la publicidad. La fotografía debería ser enseñada a través de un abordaje interdisciplinario, que permitiese el diálogo entre fotógrafos, curadores, críticos, historiadores y cientistas sociales, además de otros profesionales. La enseñanza se daría en tres niveles: el técnico (manipulación de los equipamientos, luz, revelación, experimentación), el del lenguaje (representación y expresión), y el de la investigación interdisciplinaria (análisis, crítica, síntesis). Como trabajo de conclusión para evaluarse el proceso de aprendizaje de la técnica, de experimentación y de reflexión, el alumno presentaría una carpeta con los resultados de su investigación.

El objetivo era crear un curso superior de fotografía para formar un nuevo tipo de fotógrafo en aquel contexto de redemocratización de la sociedad brasilera iniciado en 1985. Pero, fue solamente a partir de 1999 que fue reconocido por el MINISTERIO DE EDUCACIÓN y, entra en funcionamiento el primer Curso Superior de Fotografía en Brasil, creado por el SENAC de São Paulo, bajo la coordinación de Marcos Lepíscopo y Thales Trigo. El Proyecto de Ley 2.176/11, de autoría del diputado Fernando Torres (del Estado de Bahía - BA), que reglamenta la profesión de fotógrafo, fue aprobado por la Comisión de Constitución y Justicia y de Ciudadanía (CCJC) el 8 de marzo de 2014 [5]. De acuerdo con la propuesta, podrán ejercer la profesión las personas con formación en fotografía en la enseñanza superior o en la enseñanza técnica; y también los no diplomados que, a la fecha de la vigencia de la nueva ley, hayan ejercido la profesión por, en lo mínimo, dos años. Igualmente, aún es necesario un largo camino para que la ley sea efectiva.

\section{Fotoperiodismo y fotodocumental}

41 Según Sousa (2000, p. 12), fotoperiodismo en el sentido estricto se caracteriza por una actividad que busca "informar, contextualizar, ofrecer conocimiento, formar, aclarar, o marcar puntos de vista ("opinar") a través de la fotografía de acontecimientos y de la cobertura de asuntos de interés periodístico". Para este autor (2000, p. 13), el fotodocumental se diferencia del periodismo en la práctica y en el producto, más que en su finalidad. El fotodocumentalista trabaja con otra temporalidad, permitiéndole un contacto de mayor tiempo y profundidad con el asunto, el lugar y los grupos que pretende fotografiar. Utiliza la noción de proyecto, participando de la definición del asunto a ser fotografiado, haciendo investigaciones previas antes de ir a campo. Lo que le permite decidir los mejores medios y recursos técnicos a ser empleados (equipamientos, puntos de vistas etc.).

42 O fotodocumental social es la forma más común de fotodocumental, que busca abordar o investigar de forma más o menos profunda temas de interés social (conflictos políticos, guerras, migraciones, la vida de grupos outsiders, etc.) o que afecten la vida en sociedad en el largo plazo (como crímenes o desastres ambientales). 

el patrimonial que, desde el fin del siglo XIX, un discurso documental comienza a estructurarse en medio de los fotógrafos. A partir de los años 1930, al contrario, es la acepción social y política la que se destaca incontestablemente, dominando la comprensión del término hasta hoy. Ese traslado semántico está fuertemente marcado por la influencia anglo-sajona. Será en esa época que en el cine primero, y después en la fotografía, los autores británicos y norteamericanos se apoderan del vocablo francés "documentaire" transformándolo en "documentary", designando así una categoría de obras destinadas a la descripción del mundo contemporáneo y de la realidad social en particular. El término carga una connotación moral y política positiva asociada a la idea de la búsqueda de la verdad y de compromiso con lo real.

(2007, p. 406), afirma que más allá del deseo compartido de fidelidad a lo real y de una utilidad pública de las imágenes, existe un aspecto que reúne las diferentes direcciones del discurso documental que es el de desarrollarse siempre en oposición o en referencia a la fotografía de arte o un cierto estado de la fotografía de arte, con la cual él gustaría quebrar. Esa es la paradoja fundamental de ese discurso : la división 
documental que podría ser en cierta medida tomada como antónimo de artística es, esencialmente, una emanación del campo artístico.

En los años 1980, se observa un amplio movimiento de cuestionamiento político sobre el territorio, en torno de la noción de paisaje. Un movimiento interdisciplinario surge en Europa a partir del final de la década de 1970, cuando la euforia del desarrollo industrial y social de los "Treinta Gloriosos" deja espacio para una preocupación ambiental y una búsqueda de la identidad de los territorios.

El paisaje se transforma en el punto de convergencia y de traducción de todas estas cuestiones. El mismo permite reflexionar sobre los cambios visibles y sensibles, brindando un mapeo de los elementos del territorio. El paisaje parecía ofrecer un punto de vista específico, anclado en el espacio y en el tiempo. Como síntoma de la relación del hombre con su medio ambiente, el paisaje es considerado como una práctica del espacio, como una construcción cultural.

51 En Brasil, en los años 1970 y 1980, una nueva generación de fotógrafos va a dirigir su mirada hacia el paisaje del campo y de la ciudad, con la intención de pensar el territorio y sus transformaciones en el seno de un proceso de desarrollo capitalista e industrial acelerado.

\section{La fotografía de Luiz Carlos Felizardo}

Luiz Carlos Felizardo nació en 1949, en la ciudad de Porto Alegre, Rio Grande do Sul (RS). Estudió música en la escuela secundaria y llegó a considerar una carrera como concertista de piano. En 1968, empieza el curso de arquitectura en la Universidade Federal de Rio Grande do Sul (UFRGS). En 1970, comienza a trabajar para agencias de propaganda y publicidad. En 1972, compra su primera cámara de gran formato (4 x 5 pulgadas) y abandona el curso de arquitectura para dedicarse exclusivamente a la fotografía (Vásquez, 2011, p. 11-12).

Entre 1973 y 1975, por invitación de Assis Hoffmann, quien era Editor de fotografía de la empresa periodística Caldas Junior, firmaba dos páginas sobre fotografía los sábados en el periódico Folha da Manhã. Esta actividad de reflexión sobre la fotografía brasileña inspirará posteriormente la publicación de dos libros, que reunirán ensayos escritos en las décadas de 1990 y 2000 a periódicos y revistas : Relógio de ver (2000) e Imago (2010).

En 1975, en Porto Alegre, realiza su primer exposición individual en el Instituto de Arquitectos de Brasil (IAB - sección RS). En el año siguiente, la IAB lo contrató para realizar una investigación de documentación de la arquitectura regional, que daría lugar a la muestra "Arquitectura desarrollada en el espacio del sur-rio-grandense".

En 1980, Felizardo realizó cuatro exposiciones individuales en la Facultad de Arquitectura y Urbanismo de la UFRGS, con una serie de ensayos de documentación fotográfica sobre arquitectura 'vernácula' y el paisaje del sur-rio-grandense. Utilizando una cámara de 4 x 5 pulgadas, recorrió el interior de Rio Grande do Sul fotografiando paisajes y arquitecturas únicas.

56 En los años 1980, Felizardo participó en las semanas de fotografía promovido por FUNARTE y realizó una serie de exposiciones por Brasil. En 1984, recibió una beca para estudiar en los Estados Unidos CAPES/Fullbright. Había un estudiante de Frederick Sommer, en Prescott (Arizona). Experiencia que cambió su forma de pensar y crear fotografía. 
57 Felizado prefiere usar cámaras de gran formato, con más tiempo de exposición y profundidad de campo, buscando un equilibrio delicado entre luces y sombras. Explorando la riqueza de semitonos, en una fina graduación tonal de grises. Su principal característica es el rigor en la composición, en la construcción de la estructura de las imágenes, la explotación de texturas, luces y sombras. Según sus propias palabras: "A la toma de las imágenes sigue un trabajo de laboratorio delicado. El principio que uso es exponer las sombras y revelarlas con otras luces. (Entrevista concedida al autor, 28 de agosto de 2013). Felizardo buscó a través de este rigor, crear imágenes de gran delicadeza, valorar y dar importancia al paisaje, la arquitectura o el objeto fotografiado.

Tal vez la más conocida fotografía de Luiz Carlos Felizardo sea el 'Cemitério de Santa Bárbara do Sul' (1974). El trabajo es parte de un pequeño cementerio con sus tumbas y lápidas en medio del campo blanco. La imagen es llamativa por el tema, por el equilibrio compositivo, la belleza plástica de las luces de una tarde soleada, pasando por espesas nubes, centrándose en los sepulcros blanqueados en medio de la inmensidad de la Pampa. Imagen de gran equilibrio constructivo entre la claridad del sol, la inmensidad de la oscura tierra que se pierde en el horizonte, las tumbas blancas y a partir del primer plano, una carretera que bordea el cementerio y se extiende diagonalmente al más allá, donde no alcanza el ojo.

El tema es recurrente y vuelve en la obra 'Camping y cemitério' (1979), “Cemitério no Salto" (1987) y 'Linha Imperial' (1992), así como indirectamente en otras series (Felizardo, 2011).

60 Otra de sus obras más conocidas se compone de una serie de imágenes producidas en diferentes momentos sobre la Misión Jesuita de São Miguel (Brasil -RS). La relación de Felizardo con la Misión de São Miguel está vinculada con la historia de su familia. Alfredo Felizardo, padre de Luiz Carlos, trabajó en el Departamento de tierras y colonización del Estado de Rio Grande do Sul y fue él quien heredó algunas fotografías de la Catedral, entre 1925 y 1927, en ruinas y cubierta de vegetación y árboles (ramas, 2011, p. 141). También heredó de su padre una carta, del primo de éste, Luis Carlos Prestes, en la cual agradecía la imagen recibida en la cárcel (en 1942), que lo había animado, porque la permitió recordar cuando habían reunido las primeras tropas que formaron la Columna Prestes al pie de la Misión de São Miguel.

61 En 1976, Felizardo fotografió las misiones en el contexto de un amplio estudio de la arquitectura del sur de Brasil para el Instituto de los Arquitectos de Brasil (IAB-RS). Realizó otros viajes à las misiones entre 1979 y 1987. Fue entonces que participó en una exposición colectiva llamada 'la visión del artista' en celebración de los 300 años de las misiones jesuíticas. Once artistas contemporáneos de Argentina, Paraguay y Brasil han creado obras especialmente para la exposición.

62 Para esta exposición, Felizardo ideó una obra formada por una serie de ocho fotografías titulada 'como un escenario de crimen'. El título fue inspirado por un fragmento de 'Pequeña historia de la fotografía' de Walter Benjamin sobre la fotografía de Eugène Atget en Paris del fin-de-siècle (Ramos, 2011, p. 141).

Las imágenes de la serie 'Sonho e ruínas' (1987) actúan como una interrogación al observador. En ellos estamos ante al tiempo (Didi-Huberman, 2010, p. 147). Tiempo de las ruinas de un proyecto de civilización de las misiones jesuíticas y de las disputas entre las coronas de Portugal y España en América del Sur. 
de Felizardo, varios fotoperiodistas fotografiaron diferentes grupos indígenas diferentes en los años 1970 y 80, que militaron por la demarcación de sus tierras. En la obra de contemporáneos fotoperiodistas gaúchos como Assis Hoffmann (algunas de ellas publicadas en el periódico Folha da Manhã entre 1975 y 1976), se observan los conflictos entre los indígenas y los campesinos sin tierra en el noroeste del Estado de Rio Grande do Sul. paisaje de Bagé (1983-84) con el mercado público de Porto Alegre, se observa el encuentro de dos grandes temas de la fotografía de Felizardo y una síntesis del proceso de formación de identidad sur-rio-grandense, entre el campo y la ciudad.

72 Es posible establecer un paralelo entre la preocupación con el paisaje y la memoria, presente en la obra de Felizardo y los proyectos de fotografía documental de Marcos 
Santilli, realizada en los años 1970 y 1980, en Rondônia. En ellas se piensa la transformación de los paisajes y de la vida de los nativos de la región, así como las ruinas de un proyecto de la modernidad de principios del siglo XX en Rondônia : la construcción del ferrocarril Madeira-Mamoré (1907-1912).

\section{La fotografía de Marcos Santilli} representante de la fotografía documental en los años 1970-80. Era un estudiante de arquitectura en la Universidad de Brasilia, donde comenzó su formación en la fotografía. Abandonó el curso para convertirse en un reportero gráfico en los años 1970, trabajando en el Diario de Brasilia, donde tuvo contacto con Luis Humberto.

Santilli estudió fotografía en la escuela de Agfa Gevaert, en 1973, en Londres. Entre 1974 y 1978 fue miembro del equipo fotográfico de la Editora Abril. Paralelamente estudió Comunicación Visual en la Fundación Armando Alvares Penteado, São Paulo, Cine investigación y video de la New School for Social Research de Nueva York.

1977, comienza a desarrollar un proyecto de investigación y documentación fotográfica en los Estados de Rondônia y Acre. Proyecto que contó con la ayuda de becas de investigación de la John Simon Guggenheim Memorial Foundation, en 1981, de la Fundación Vitae, en 1988 y la Comisión Fulbright en 1989. Su obra de documentación originó la publicación de tres libros: Àre, 1987; Madeira-Mamoré Imagem e Memória, 1987 ; y Amazon - A Young Reader's Look at the Last Frontier, 1991.

Santilli se destacó en el escenario de la fotografía documental con ensayos sobre transformaciones sociales y ambientales que se producen en Acre y Rondônia en las décadas de 1970 y 80 .

atiliza el color y la luz de la región para abordar la exuberancia de la Amazonía y el trabajo cotidiano de sus habitantes sin apelación a lo exótico. Reúne en sus imágenes las prácticas tradicionales locales y la evidencia de la presencia violenta de la civilización. Según Benjamin, los mismos documentos de civilización son también documentos de la barbarie.

Formalmente, el trabajo llama la atención por la saturación de color, el equilibrio y simetría de los encuadramientos. Santilli utiliza un juego de luces y sombras, con colores y texturas para fotografiar las locomotoras, los edificios abandonados y reocupados, y los rostros de ex trabajadores.

Las imágenes encuadran en primer plano las superficies metálicas de las locomotoras corroídas por el tiempo, con letras y números borrados que las identifican, con la alta hierba alrededor, destacando así el quiebre y el abandono del proyecto de la modernidad. la lucha por la tierra y por la sobrevivencia en un lugar tan rico y al mismo tempo tan hostil.

81 La ruina de un proyecto de la modernidad en la selva - vagones de ferrocarril, edificios y estructuras abandonadas y tomadas por la exuberante vegetación (cárcel, hospital, estación de tren), el uso de los carriles para el transporte de los residentes de la región 
- la ocupación de los edificios por los nuevos residentes, quienes insisten en quedarse y buscar un medio de vida en medio del abandono, la ruina y las luchas por la tierra.

Las imágenes de la carretera y el camión aparecen como los nuevos símbolos de modernidad, de integración y de la devastación de las tierras indígenas. El fotógrafo también da el punto de vista del proceso de integración forzada de los indígenas y su marginación en el proceso de producción capitalista : la enfermedad, la prostitución, el subempleo, etc.

\section{Consideraciones finales}

La contradicción presente en la discusión sobre la figura del autor y autoría en fotoperiodismo y fotografía documental, surge en el momento en que se hace una crítica a la figura del autor en el campo de la teoría literaria con Roland Barthes y en las Humanidades con Michel Foucault con un énfasis en el papel del lector y el observador.

En los años 1970, también hubo internacionalmente y, sobre todo en los Estados Unidos, cierto consenso sobre el agotamiento de las posibilidades de la fotografía documental. Fotógrafos como Martha Rosler y Alan Sekula realizaron obras en que se hizo la crítica de los usos sociales y políticos de la fotografía documental.

Sin embargo, en Brasil y en América Latina las dictaduras militares, la situación de excepción, la política de modernización capitalista extremadamente desigual, dramáticas transformaciones del paisaje y de las relaciones sociales en el campo y en la ciudad, traerían un nuevo aliento al lenguaje de la fotografía documental en su vertiente social y también artística.

En este texto, he propuesto una serie de preguntas para el debate sobre la expansión y reorganización del campo de la fotografía en Brasil en los años 1970 y 1980. La producción fotográfica del período continúa cuestionándonos y nos propone nuevas perspectivas sobre los diferentes paisajes e identidades en transformación, a través de una trama que convoca a otras imágenes, otras memorias, imaginarios y otras luchas que se libraron en estos paisajes del campo y de las ciudades brasileñas, así como también en los territorios de la fotografía.

BAITZ Rafael, Um continente em foco: a imagem fotográfica da América latina nas revistas semanais brasileiras (1954-1964), São Paulo, Humanitas/FFLCH/USP, 2003.

BARBOSA Marialva, História Cultural da Imprensa (Brasil - 1900-2000), Rio de Janeiro, Mauad $\mathrm{X}, 2007$.

BENEDICTO Nair, Ciclo de Palestras Sobre Fotografia. Rio de Janeiro, Sindicato dos Jornalistas, FUNARTE,1983.

BENJAMIN Walter, Water Benjamin, 2a. Ed. org. e trad. Flávio R. Kothe, São Paulo, Ática, 1991.

BERTHO Raphaële, La Mission Photographique DATAR. Un laboratoire du paysage contemporain, Paris, La Documentation Française, 2013.

CARVAlHo Carlos, 6. FestFoto: Festival Internacional de Fotografia de Porto Alegre [A experiência Coletiva], Porto Alegre, Imagem Brasil, 2012.

CHEVRIER Jean-François, La fotografía entre las bellas artes y los medios de comunicación, Barcelona, Editorial Gustavo Gili, 2007. 

Naif, 2004. Vozes, 1994. INFoto, 1986. Fluminense. Contexto, 2008.

CHIARELLI Tadeu, Identidade/não-identidade: A fotografia brasileira hoje, in Arte internacional brasileira. CHIARELLI T., 2 ${ }^{\text {a }}$ ed. São Paulo, Lemos Editorial, 2002.

Coelho Maria Beatriz M. de V. "O campo da fotografia profissional no Brasil", in Varia Historia, Belo Horizonte, vol. 22, nº35, jan/jun 2006, p.79-99.

COELHO Maria Beatriz R., Imagens da nação: brasileiros na fotodocumentação de 1940 até o final do século XX, Belo Horizonte, UFMG, 2012.

COSTA Helouise, Da fotografia como arte à arte como fotografia : a experiência do Museu de Arte Contemporânea da USP na década de 1970, in Anais do Museu Paulista, São Paulo, jul.-dez. 2008, v. 16, n. 2, p. 131-173.

COSTA Helouise; BURGI Sérgio (orgs.), As origens do fotojornalismo no Brasil : um olhar sobre o Cruzeiro (1940-1960), Rio de Janeiro, Instituto Moreira Salles, 2012.

costa Helouise; SILVA Renato Rodrigues , A fotografia moderna no Brasil, São Paulo, Cosac

DEBRAY Régis. Vida e morte da imagem. Uma história do Olhar no Ocidente, Petrópolis, RJ :

FERNANDES JÚNIOR Rubens, Labirinto e identidades: panorama da fotografia no Brasil (1946-98), São Paulo, Cosac \& Naify, 2003.

FICO Carlos; FEREIRA Marieta de Moraes; ARAÚJo Maria Paula; QUADRAT Samantha Viz (orgs.), Ditadura e Democracia na América Latina. Balanço Histórico e Perspectivas, Rio de Janeiro, FGV, 2008.

FRIzOT Michel (Ed.), Nouvelle Histoire de la photographie, Paris, Adam Biro/Larousse, 2001.

FUNARTE, Proposta para uma Política Nacional da Fotografia, Rio de Janeiro, FUNARTE/

GELDER Hilde Van; WESTGEEST Helen, Photography Theory in Historical Perspective. Case studies from Contemporary Art. Chichester, West Sussex, U.K, Blackwell, 2011.

HUMBERTo Luis, Fotografia: universos e arrabaldes, Rio de Janeiro, FUNARTE/Núcleo de Fotografia, 1983. (Coleção Luz \& Reflexão).

LOUZADA Silvana, Prata da casa: fotógrafos e fotografia no Rio de Janeiro (1950-1960), Rio de janeiro, 2009. Tese (Doutorado em Comunicação) IACS - Universidade Federal

LUGON Olivier, Le style documentaire. D'Auguste Sander à Walker Evans, 1920-1945, 3 ed. Paris, Editions Macula, 2001.

LUGON Olivier, L'esthétique du document. 1890-2000: Le réel sous toutes ses formes, in L'art de la Photographie. Des origens à nos jours, GUNTHERT André; POIVERT Michel, Paris, Citadelles, 2007. p. 357-422

MAGALHÃEs Ângela; PEREGRINo Nadja Fonseca, Fotografia no Brasil: um olhar das origens ao contemporáneo, Rio de Janeiro, Funarte, 2004.

MARIEN Mary Warner, Photography. A Cultural History, 2nd ed. Upper Saddle River (N.J) : Pearson Prentice Hall, 2006.

MARTINS Ana Luiza; LUCA Tânia Regina de (orgs.), História da Imprensa no Brasil, São Paulo,

MARTINS Juca, Juca Martins : Antologia Fotográfica, Rio de Janeiro, Dazibao, 1990. 
114 MAUAD Ana M., Imagens Possíveis: fotografia e memória em Claudia Andujar, in Revista Eco-Pós (Online), v. 15, p. 124-146, 2012a.

MOREL Gaëlle, Le photoreportage d'autuer. L'institution culturelle de la photographie en France depuis les années 1970, Paris, CNRS, 2006.

116 MUNTEAL Oswaldo, GRANDI Larissa, A imprensa na História do Brasil: fotojornalismo no século XX, Rio de Janeiro, PUC- Rio de Janeiro, 2005.

117 PAIVA Joaquim, Olhares refletidos, Rio de Janeiro, Ágil/Dazibao, 1989.

118 POIVERT Michel, La photographie contemporaine, Paris, Flammarion, 2002.

119 POLLAK Michael, "Memória e Identidade Social", in Estudos Históricos, Rio de janeiro, vol. 5, n. 10, 1992, 200-215. RouilLÉ André, A fotografia. Entre documento e arte contemporânea, São Paulo, SENAC, 2009. sousa Jorge Pedro, Uma história crítica do fotojornalismo occidental, Chapecó, Argos, Florianópolis, Letras Contemporâneas, 2004. TAGG John, El peso de la representación: ensayos sobre fotografias e historias, Barcelona, Editorial Gustavo Gili, 2005.

\section{NOTAS}

1. En las revistas ilustradas de gran circulación nacional, tales como O Cruzeiro y Manchete. Entre otros ver: BAITZ, Rafael. Um continente em foco : a imagem fotográfica da América latina nas revistas semanais brasileiras (1954-1964). São Paulo : Humanitas/FFLCH/USP, 2003. 2. Según Barbosa (2007, p. 198), “a inicios de los años 1970, el mayor contingente de periódicos del país se ubicaba en São Paulo (229 periódicos y 210 revistas). Rio de Janeiro ocupaba la cuarta posición, atrás de Rio Grande do Sul y de Minas Gerais, habiendo editado en aquellos años 39 periódicos (Veículos Brasileiros de Publicidade, 1971)".

3. Estas siglas corresponden a los siguientes Estados de Brasil : Rio de Janeiro, Distrito Federal, Pernambuco, Pará, Paraná, Minas de Gerais y São Paulo respectivamente.

4. Nació en la ciudad de Rio de Janeiro, en 1934, pero reside en Brasilia desde 1962, habiendo integrado el grupo de profesores fundadores de la Universidad de Brasilia (UnB), primero como profesor de arquitectura y urbanismo y, posteriormente, de fotografía. Disciplina en la cual fue el primer profesor titular en una universidad brasilera, en 1992. Informaciones del Site de la FUNARTE, acceso el 26/9/2014: http://www.funarte.gov.br/brasilmemoriadasartes/acervo/ infoto/biografia-de-luis-humberto/

5. El proyecto, aprobado en el último martes (8), describe el fotógrafo como el profesional que, con el uso de la luz, registra imágenes estáticas o dinámicas en material fotosensible o medios digitales, con la utilización de equipamientos ópticos apropiados, siguiendo un proceso manual, electromecánico o de informática, hasta su finalización. Ver : http://agenciabrasil.ebc.com.br/ geral/noticia/2014-04/fds-regulamentacao-da-profissao-de-fotografo-sera-definida-pelo-senado 


\section{RESÚMENES}

El campo de la fotografía en Brasil en los años 1970 se caracterizó por un proceso de expansión, profesionalización, al mismo tiempo que se hizo más complejo, tanto en el campo periodístico como en el campo artístico. La investigación busca problematizar la reorganización del campo fotográfico en Brasil, en los años 1970, en especial, la producción de imágenes situadas entre los campos del fotoperiodismo y de la fotografía documental, en el contexto sociopolítico de un país en transformación, debido a la lucha por la abertura política y los movimientos sociales. Los fotógrafos se comprometieron en la construcción de una nueva visión para la nación. En este proceso, la prensa, y en especial, el fotoperiodismo tuvo un papel fundamental en la denuncia de la represión, de la censura y de las desigualdades sociales. El artículo está dividido en cinco partes. Primero tratar de trazar un panorama del campo profesional de la fotografía en los años 1970 y 80 . Luego, se aborda el cambio en la formación de fotógrafos cuando la fotografía se enseña en cursos universitarios y se crean las primeras escuelas de fotografía. Más tarde, se analizan los conceptos y prácticas de fotoperiodismo y fotografía documentalista. Finalmente, presentase dos estudios de caso sobre la obra fotográfica de Luiz Carlos Felizardo y de Marcos Santilli.

The field of photography in Brazil in the 1970s was characterized by a process of expansion, professionalization, at the same time that became more complex, both in the journalistic field and in the artistic field. Research seeks to problematize the reorganization of the photographic field in Brazil, in the 1970s, in particular, the production of images within the fields of photojournalism and documentary photography, in the socio-political context of a country in transformation, due to the struggle for the political opening and social movements. The photographers committed in the construction of a new vision for the nation. In this process, the press, and especially photojournalism had a fundamental role in the denunciation of repression, censorship and social inequalities. The article is divided into five parts. First try to draw a picture of the professional field of photography in the 1970 and 1980s. Then, the change in the formation of photographers when photography is taught in University courses and created the first schools of photography. Later, discussed the concepts and practices of photojournalism and documentary photography. Finally, submit two case studies on the photographic work of Luiz Carlos Felizardo and Marcos Santilli.

\section{ÍNDICE}

Palabras claves: fotografía, fotoperiodismo, fotografía documental, Luiz Carlos Felizardo, Marcos Santilli

Keywords: photography, photojournalism, documentary photography, Luiz Carlos Felizardo, Marcos Santilli

\section{AUTOR}

\section{CHARLES MONTEIRO}

Doctor en Historia Social (PUC-SP, 2001) con pos-doctorado en Historia Social y Cultural del Arte en la Universidad de París 1-Panthéon Sorbonne INHA (2013-2014), profesor e investigador del 
Departamento de Historia y del Programa de Pos-Grado en Historia de la Pontifícia Universidade Católica do Rio Grande do Sul, investigador PQ 2 del CNPQ-MCT 